\title{
Evaluation of the anti-inflammatory activity of Garcinia kola capsules on Gonarthrosis and low back pain
}

\author{
Happi Monthé Adelaïde Nathalie 1, Djoko Ernest 1,*and Ngandeu Singwe Madeleine 2 \\ ${ }^{1}$ Galenic pharmacy laboratory, "Université des Montagnes". Bangangté- Cameroon. \\ 2 Faculty of Medicine, Department of Internal Medicine - University of Yaoundé 1 - Cameroon.
}

International Journal of Biological and Pharmaceutical Sciences Archive, 2022, 03(01), 031-039

Publication history: Received on 01 January 2022; revised on 08 February 2022; accepted on 10 February 2022

Article DOI: https://doi.org/10.53771/ijbpsa.2022.3.1.0025

\begin{abstract}
Garcinia kola (Clusiaceae) commonly known as "Bitter cola", is a shrub from the forests of Central and East Africa. In Cameroon it is found in Mbam and Moungo divisions. Garcinia kola seeds are widely consumed by local populations, sometimes in search of a simple pleasure, sometimes in search of its multiple pharmacological properties. The main objective of this study was to evaluate the anti-inflammatory activity and the tolerance of Garcinia kola capsules (BTK capsule *) on gonarthrosis and lumbago. A pilot study was carried out on 90 patients (68 women and 22 men). The patients were divided into 3 groups. Patients in the first group received Garcinia kola capsules at a dose of 800 mg per day while those in the second group received Diclofenac tablets at a dose of $100 \mathrm{mg}$ per day and those in the third group received placebo capsules. The judgement criteria were highly sensitive C Reactiv Protein (HS-CRP), sedimentation rate (SR), visual analogue scale (VAS). The test significance threshold was set at a probability of $\mathrm{p}<0.05$. The first group (Garcinia kola) showed: HS-CRP $\mathrm{p}<0.002$, VAS $\mathrm{p}<0.001$ and SR: $\mathrm{p}<0.003$; the second group (Diclofenac): HS-CRP $\mathrm{p}=$ 0.001 , VAS $p<0.001$ and SR $p<0.001$. For the placebo group: HS-CRP $p=0.916$, VAS $p=0.002$ and SR $p=0.829$. These results confirm that Garcinia kola at a dose of $400 \mathrm{mg}$ twice a day has anti-inflammatory properties similar to those of Diclofenac at $50 \mathrm{mg}$ twice a day. Biological tests revealed that Garcinia kola (BTK *) capsules have no harmful effects on kidney function, liver function, blood sugar and blood pressure. Libido was increased in men.
\end{abstract}

Keywords: Anti-inflammatory; Garcinia kola; Diclofenac; Gonarthrosis; Lumbagia.

\section{Introduction}

Garcinia kola (Clusiaceae) commonly known as "Bitter cola", is a medium-sized tree found in the forests of the regions of Central and East Africa. It produces fruits of reddish, yellowish or orange color, containing 2 to 4 seeds [1]. The large consumption of its seeds has given rise to numerous studies which have shown that they contain phenolic compounds, steroids, benzophenones, flavonoids, tannins, alkaloids, anthraquinones, saponosides, anthocyanins and heterosides, as well as minerals such as: phosphorus, magnesium, calcium and potassium [2,3,]. Other studies have shown their pharmacological properties: antipyretics [4], anti-inflammatory, analgesics [5], hepatoprotectives, antidepressants, antioxidants, antidiabetics, antimicrobials, antiulcer drugs, antidiarrheals, antiemetics, anti-hypertensives, anti-asthma $[6,7,8]$; they are known to be aphrodisiacs for men; they can suppress and delay fertility in women [2,9]. Olaleye et al studied the analgesic and anti-inflammatory activity of Garcinia kola seeds and found that the defatted extract of the seeds exhibits anti-nociceptive properties at a dose of $200 \mathrm{mg} / \mathrm{kg}$ [5].

Olayinka et al discovered that Garcinia kola at a dose of $200 \mathrm{mg}$ has a significant analgesic / anti-inflammatory effect with satisfactory results in the medium term [10].

\footnotetext{
${ }^{*}$ Corresponding author: Djoko Ernest

Galenic pharmacy laboratory, “Université des Montagnes”. Bangangté- Cameroon.

Copyright $(2022$ Author(s) retain the copyright of this article. This article is published under the terms of the Creative Commons Attribution Liscense 4.0.
} 
Rheumatic diseases are a form of inflammatory disease and a major cause of disability worldwide. Knee osteoarthritis is by far the most common etiology of knee pain after 50 years. Its diagnosis is above all based on a careful examination of the patient, a good examination of the knee and a careful reading of the radiographs [11].

The majority of adults experience at least one episode of low back pain in their lifetime. Chronic low back pain (lumbago) has become a public health problem, due to its significant morbidity and its socio-economic burden. They clinically result in low back pain leading to functional limitation of trunk mobility [12]. A recent publication by Djoko et al presented the development of Garcinia kola capsules called BTK* [13]. The pharmacological properties of the seeds of garcinia kola suggesting a very promising future for these capsules, the present study positioned itself in the continuity and wanted to evaluate the effectiveness and the tolerance of these capsules during the use in two rheumatological pathologies, knee osteoarthritis and low back pain.

\section{Material and methods}

\subsection{Capsules}

The Garcinia kola capsules used were BTK * capsules containing $400 \mathrm{mg}$ of Garcinia kola powder, manufactured one year earlier by Djoko et al [13]

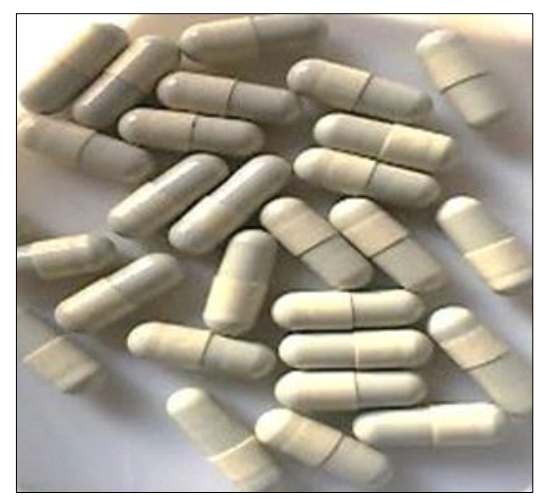

Figure 1 Garcinia kola capsules: BTK [13]

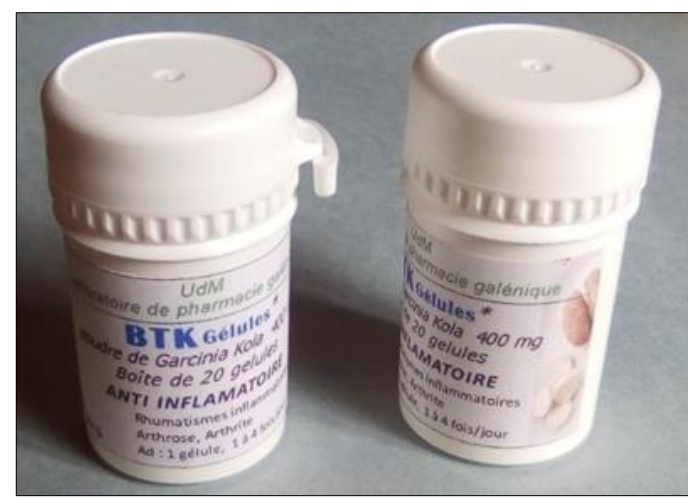

Figure 2 Packaged Garcinia kola capsules [13]

The BTK * capsules were evaluated in parallel with the enterosoluble tablets of diclofenac $50 \mathrm{mg}$ from Sandoz Laboratories.

\subsection{Study population}

The target population consisted of patients who came for consultation at the Douala General Hospital in the period from February to May 2018 and for whom the diagnosis of low back pain and / or knee osteoarthritis was made.

\subsection{Technical sheet}

The survey form included a lot of informations, in particular the socio-demographic characteristics, anthropometric, clinical and biological data, the biological examinations on Day 0 and Day15, the visual analogue scale (VAS) on Day 0 and Day15, the evolution of symptoms and side effects.

\subsection{Method}

\subsubsection{Sampling}

This study is a pilot study with a double-blind, randomized controlled trial, on three batches of patients: a batch A, receiving Garcinia kola (BTK) capsules at a dose of $800 \mathrm{mg}$ per day divided into two intakes, a batch B receiving as reference substance, Diclofenac at a dose of $100 \mathrm{mg}$ divided into 2 doses per day and a batch $\mathrm{C}$ receiving a placebo. This placebo consisted of the basic treatment without anti-inflammatory drugs administered to all patients in the study. 


\subsubsection{Inclusion criteria}

Included were patients with low back pain, patients with stage 2 or 3 knee osteoarthritis according to Lawrence and Kellgren, aged 18 to 85, and not under anti-inflammatory treatment.

\subsubsection{Collection of data}

\section{Administration of capsules}

The recruitment of patients was followed by the signing of the informed consent form but the prerequisite for the study was the ethical clearance obtained from the institutional committee of "Université des Montagnes" and the research authorization obtained from the director of General Hospital of Douala. All patients were seen by the same rheumatologist. Each patient received standard treatment prescribed by the rheumatologist; this treatment could combine, depending on the symptomatology and the intensity of the patient's pain, a level 1 analgesic (paracetamol) or a level 2 analgesic (codeine or tramadol). Muscle relaxants (metocarbamol, thiocolchicoside) or co-analgesics (amitriptyline, clonazepam, pregabalin, vit B were given when there was a question of neuropathic pain. After signing the informed consent form, each patient was interviewed, gave blood for laboratory tests and was invited to return after 15 days for another interview and blood test. Thus, on Day 0 were performed the HS-CRP and the SR. On Day 15 were performed HS-CRP, SR, serum creatinine, blood sugar, alanine amino transferase (ALAT) and aspartate amino transferase (ASAT). Group B patients complaining of stomach pain received a Proton Pump Inhibitor at the beginning of treatment.

\section{Examinations carried out}

Visual analogue scale (VAS). It is a ruler graduated from 0 to $10 \mathrm{~cm}$ with images expressing facial expressions in the event of pain. For interpretation, 0 means no pain; from 1 to 3: slight pain; from 4 to 6: moderate pain; from 7 to 10 : severe pain.

\section{Biological examinations}

Ultra Sensitive C Reactive Protein C (HS-CRP): The HS-CRP is a quantitative turbidimetric test to measure the low level of C-reactive protein in human serum or plasma. Specific anti-human C-reactive protein (CRP) coated latex particles clump together when mixed with samples containing CRP. Agglutination causes a change in absorbance, depending on the CRP content of the patient sample, which can be quantified by comparison with a standard of known CRP concentration.

Sedimentation Rate (SR) by the Westergreen method: This is to determine the rate of fall of red blood cells suspended in plasma. The blood made incoagulable is placed in vertical calibrated tubes. The sedimentation rate is the height of the plasma column devoid of red blood cells after a given time.

Creatinine: Creatinine forms a complex with the alkaline picrate. A kinetic assay eliminates interference due in particular to bilirubin. Normal values in the serum: Male: 7 to $13 \mathrm{mg} / \mathrm{l}$ and Female: 6 to $11 \mathrm{mg} / \mathrm{l}$.

ALAT: Alanine amino transferase (ALAT) initially called glutamic pyruvic transaminase (GPT) catalyzes the reversible transfer of an amine group from alanine to alpha-ketoglutarate with the formation of glutamate and pyruvate. The pyruvate produced is reduced to lactate in the presence of lactate dehydrogenase (LDH) and NADH:

ASAT: Aspartate amino transferase (ASAT), originally called glutamate oxaloacetic transaminase (GOT) catalyzes the reversible transfer of an amine group from aspartate to alpha-ketoglutarate to form glutamate and oxalacetate. The oxalacetate produced is reduced to malate in the presence of malate dehydrogenase (MDH) and NADH.

\subsubsection{Data analysis}

The qualitative variables were the results of the quality controls, the socio-demographic characteristics, the personal history of the patients, the site and type of pain, the grade of knee osteoarthritis, the body mass index (BMI), side effects, treatment undertaken, biological control examinations on day15. The quantitative variables were VAS, HS-CRP, and SR.

The data were inserted into an input mask designed using Epi info software version 3.5.3, then analyzed by SPSS software version 22. The results obtained were presented in tabular form. Qualitative data were expressed in numbers. The difference between the means of quantitative variables was estimated by calculating the percentage difference at 
Day0 and Day15. Student's (T) test for paired samples was used for comparison of quantitative variables. The test significance threshold was set at a probability $\mathrm{p}<0.05$.

\section{Results}

\subsection{Quality control of garcinia kola capsules (BTK *)}

The disintegration time was 4 min 40s and was in accordance with the requirements of the European pharmacopoeia.

Uniformity of mass: The masses of the contents of the capsules are collated in Table 1.

Table 1 Masses of the contents of the capsules

\begin{tabular}{|l|l|l|l|}
\hline $\mathrm{M} 1=0.404 \mathrm{~g}$ & $\mathrm{M} 6=0.401 \mathrm{~g}$ & $\mathrm{M} 11=0.402 \mathrm{~g}$ & $\mathrm{M} 16=0.402 \mathrm{~g}$ \\
\hline $\mathrm{M} 2=0.381 \mathrm{~g}$ & $\mathrm{M} 7=0.404 \mathrm{~g}$ & $\mathrm{M} 12=0.400 \mathrm{~g}$ & $\mathrm{M} 17=0.404 \mathrm{~g}$ \\
\hline $\mathrm{M} 3=0.403 \mathrm{~g}$ & $\mathrm{M} 8=0.404 \mathrm{~g}$ & $\mathrm{M} 13=0.399 \mathrm{~g}$ & $\mathrm{M} 18=0.400 \mathrm{~g}$ \\
\hline $\mathrm{M} 4=0.404$ & $\mathrm{M} 9=0.405 \mathrm{~g}$ & $\mathrm{M} 14=0.404 \mathrm{~g}$ & $\mathrm{M} 19=0.400 \mathrm{~g}$ \\
\hline $\mathrm{M} 5=0.406 \mathrm{~g}$ & $\mathrm{M} 10=0.404 \mathrm{~g}$ & $\mathrm{M} 15=0.404 \mathrm{~g}$ & $\mathrm{M} 20=0.404 \mathrm{~g}$ \\
\hline
\end{tabular}

The average mass of powder per capsule was $M=\frac{\sum M i}{20}=0.402 \mathrm{~g}$

This average mass has led to a tolerable deviation of $\mathrm{e}=7.5 \%$, hence the limits

$\mathrm{M}-\mathrm{e} \%=0.402-(0.075 \times 0.402)=0.371 \mathrm{~g}$

$\mathrm{M}+\mathrm{e} \%=0.402+(0.075 \times 0.402)=0.432 \mathrm{~g}$

None of the powder masses in the hard capsules deviated from the $\mathrm{M} \pm \mathrm{e} \%$ range. The capsules complied with the recommendations of the European Pharmacopoeia for uniformity of mass.

Microbiological control: After 24 hours in an oven at $37^{\circ} \mathrm{C}$, no microorganism growth was observed.

\subsection{Socio-demographic characteristics}

\subsubsection{Sample}

Of the 135 patients registered at the rheumatology department of the Douala General Hospital during the study period, 12 were not recruited because they had taken an anti-inflammatory drug in the 10 days preceding the consultation and 3 had refused to participate in the study; 30 dropped out before the end of the study. So the sample was 90.

\subsubsection{Breakdown by gender}

Table 2 shows that women represented $70.3 \%$ of cases of low back pain and $88.5 \%$ of cases of knee osteoarthritis. The sex most represented in the sample was female with a number of 68 out of 90 patients, or $75.55 \%$.

Table 2 Breakdown by sex

\begin{tabular}{|l|l|l|}
\hline \multicolumn{1}{|c|}{ sex } & Low back pain & Gonarthrosis \\
\hline Women & $4570.3 \%$ & $2388.5 \%$ \\
\hline Men & $1929.7 \%$ & $311.5 \%$ \\
\hline total & $64100 \%$ & $26100 \%$ \\
\hline
\end{tabular}




\subsubsection{Age distribution}

According to Table 3, the mean age was $64.1 \pm 13.7$ years for LBP and $68.3 \pm 11.0$ years for Gonarthrosis.

Table 3 Age of patients

\begin{tabular}{|c|c|c|c|c|c|c|}
\hline & $\mathbf{n}$ & Average age & Typical e cart & Min age & Max age & Median age \\
\hline Low back pain & 64 & 64.1 & 13.7 & 35.0 & 85.0 & 62.5 \\
\hline Gonarthrosis & 26 & 68.3 & 11.0 & 39.0 & 85.0 & 72.5 \\
\hline
\end{tabular}

\subsubsection{Distribution by level of education and occupation}

The majority of patients with low back pain had dropped out of primary school (39.1\%) and were mostly housewives $(42.2 \%)$. Unlike the latter, the patients suffering from Gonarthrosis had mostly a secondary education level (42.3\%) and were mostly housewives $(61.5 \%)$.

\subsection{Patient clinical features}

3.3.1. Distribution according to the body mass index (BMI):

Table 4 shows that in the two pathologies more than half of the participants were obese: $64.1 \%$ for low back pain and $73.1 \%$ for knee osteoarthritis.

Table 4 Distribution according to the body mass index.

\begin{tabular}{|c|c|c|c|c|c|}
\hline \multicolumn{2}{|c|}{ BMI $\left(\mathbf{k g} / \mathbf{m}^{2}\right)$} & \multicolumn{2}{c|}{ Lumbagia } & \multicolumn{2}{c|}{ gonarthrosis } \\
\hline$<18.5$ & Thinness & $0 \%$ & $0 \%$ & 0 & $0 \%$ \\
\hline $18.5-25$ & Ideal weight & 0 & $0 \%$ & 0 & $0 \%$ \\
\hline $26-30$ & Overweight & 23 & $35.9 \%$ & 7 & $26.9 \%$ \\
\hline$>30$ & Obesity & 41 & $64.1 \%$ & 19 & $73.1 \%$ \\
\hline & total & 64 & $100 \%$ & 26 & $100 \%$ \\
\hline
\end{tabular}

\subsubsection{Breakdown by comorbidity}

Patients with a history of joint pain were the most numerous: $45.5 \%$ for low back pain and $50.0 \%$ for knee osteoarthritis (Table 5).

Table 5 Background

\begin{tabular}{|l|l|l|l|l|}
\hline History of & \multicolumn{2}{|c|}{ Low Back Pain } & \multicolumn{2}{c|}{ gonarthrosis } \\
\hline HTA & 23 & $35.9 \%$ & 3 & $11.5 \%$ \\
\hline Diabetes & 5 & $7.8 \%$ & 0 & $0 \%$ \\
\hline Joint pain & 29 & $45.3 \%$ & 13 & $50.0 \%$ \\
\hline alcohol & 41 & $64.1 \%$ & 19 & $72.1 \%$ \\
\hline tobacco & 4 & $6.3 \%$ & 0 & $0 \%$ \\
\hline
\end{tabular}

\subsubsection{Breakdown by duration of symptoms}

As shown in Table 6 the disease was already chronic ( $>24$ months) for the majority of patients (> 60\%) at the time of the study. 
Table 6 Distribution according to the duration of symptoms

\begin{tabular}{|l|l|l|l|l|}
\hline Duration of symtoms & \multicolumn{2}{|c|}{ Low Back Pain } & \multicolumn{2}{c|}{ Gonarthrosis } \\
\hline$<3$ months & 3 & $4.7 \%$ & 1 & $3.8 \%$ \\
\hline $3-12$ months & 6 & $9.4 \%$ & 2 & $7.7 \%$ \\
\hline $12-24$ months & 14 & $21.9 \%$ & 7 & $26.9 \%$ \\
\hline$>24$ months & 41 & $64.1 \%$ & 16 & $61.5 \%$ \\
\hline Total & 64 & $100 \%$ & 26 & $100 \%$ \\
\hline
\end{tabular}

\subsection{Breakdown by type of pain}

According to Table 7 the pain was mainly mechanical: $53 \%$ for low back pain and $60 \%$ for knee osteoarthritis.

Table 7 Type of pain

\begin{tabular}{|l|l|l|l|l|}
\hline Type of pain & \multicolumn{2}{|c|}{ Low Back Pain } & \multicolumn{2}{c|}{ Gonarthrosis } \\
\hline Mixed & 34 & $46.9 \%$ & 5 & $19.2 \%$ \\
\hline Mechanical & 30 & $53.1 \%$ & 21 & $80.8 \%$ \\
\hline Total & 64 & $100 \%$ & 26 & $100 \%$ \\
\hline
\end{tabular}

\section{Efficiency of the two products}

\subsection{Distribution according to treatment}

Garcinia (BTK*): Table 8 indicates that garcinia has substantially the same effectiveness on the 2 pathologies, regardless of the assessment method $(\mathrm{p}<0.05)$

Table 8 Evolution of variables for patients under BTK *

\begin{tabular}{|l|c|c|c|c|}
\hline & Pathology & Average Day 0 & Average day 15 & p-value \\
\hline \multirow{2}{*}{ VAS } & L & 7.2 & 5.4 & $<0.001$ \\
\cline { 2 - 5 } & G & 7.2 & 5.3 & 0.001 \\
\hline \multirow{2}{*}{ HS-CRP } & L & 4.8 & 3.1 & 0.003 \\
\cline { 2 - 5 } & G & 4.9 & 3.2 & 0.029 \\
\hline \multirow{2}{*}{ SR } & L & 37 & 31.4 & 0.003 \\
\cline { 2 - 5 } & G & 36.5 & 34.3 & 0.003 \\
\hline
\end{tabular}

Table 9 Evolution of variables for patients on DICLOFENAC

\begin{tabular}{|l|c|c|c|c|}
\hline & Pathology & Average day 0 & Average day 15 & p-value \\
\hline \multirow{2}{*}{ VAS } & L & 7 & 5.3 & $<0.001$ \\
\cline { 2 - 5 } & G & 9 & 7.4 & 0.029 \\
\hline \multirow{2}{*}{ HS-CRP } & L & 4.2 & 2.6 & 0.003 \\
\cline { 2 - 5 } & G & 3.1 & 1.8 & 0.039 \\
\hline \multirow{2}{*}{ SR } & L & 36.2 & 31.9 & 0.003 \\
\cline { 2 - 5 } & G & 36.5 & 32 & 0.041 \\
\hline
\end{tabular}

p-value $<0.05$ for the 3 evaluated parameters. 
Diclofenac: Like garcinia, diclofenac has comparable efficacy for both pathologies, regardless of the method used (table 8).

Placebo: Table 10 shows the ineffectiveness of the placebo except for the VAS. This is to be blamed on the subjectivity of the VAS.

Table 10 Evolution of variables for patients on placebo

\begin{tabular}{|c|c|c|c|c|}
\hline & Pathology & Day 0 average & Day15 average & p-value \\
\hline \multirow{2}{*}{ VAS } & $\mathrm{L}$ & 6.9 & 6.3 & 0.18 \\
\hline & G & 7.5 & 6.3 & 0.002 \\
\hline \multirow{2}{*}{ HS-CRP } & $\mathrm{L}$ & 4.2 & 4.1 & 0.922 \\
\hline & $\mathrm{G}$ & 5.1 & 5 & 0.96 \\
\hline \multirow{2}{*}{ SR } & $\mathrm{L}$ & 38.8 & 38.6 & 0.834 \\
\hline & $\mathrm{G}$ & 37.2 & 37 & 0.91 \\
\hline
\end{tabular}

\subsection{Tolerance of the two products}

Breakdown by side effects. The side effects table (Table 11) shows that drowsiness was common to all patients, and that the stimulation of libido which was specific to the BTK* group. In addition, in the BTK group, the 5 patients who at the begining of treatment complained of stomach burns no longer had to complain during treatment. This problem did not arise for patients on diclofenac because they were receiving enterosoluble diclofenac tablets.

Table 11 Side effects

\begin{tabular}{|l|c|c|c|c|}
\hline Effects & Pathologies & BTK* $^{*}$ & Diclofenac & Placebo \\
\hline \multirow{2}{*}{ Drowsiness } & $\mathrm{L}$ & 4 & 6 & 5 \\
\cline { 2 - 5 } & $\mathrm{G}$ & 3 & 2 & 4 \\
\hline \multirow{2}{*}{ libido Stimulation } & $\mathrm{L}$ & 3 & 0 & 0 \\
\cline { 2 - 5 } & $\mathrm{G}$ & 3 & 0 & 0 \\
\hline \multirow{2}{*}{ Diarrhea } & $\mathrm{L}$ & 0 & 2 & 0 \\
\hline \multirow{2}{*}{ Constipation } & $\mathrm{G}$ & 0 & 0 & 2 \\
\cline { 2 - 5 } & $\mathrm{L}$ & 0 & 0 & 2 \\
\cline { 2 - 6 } & $\mathrm{G}$ & 0 & 0 & 1 \\
\hline
\end{tabular}

\subsection{Distribution according to control examinations}

Table 12 Control examinations

\begin{tabular}{|c|c|l|l|l|l|}
\hline \multirow{2}{*}{ Examinations } & State & \multicolumn{2}{c|}{ Lombalgo } & \multicolumn{2}{c|}{ Gonarthrosis } \\
\hline \multirow{3}{*}{ Plasma creatinine } & Normal & 64 & $100 \%$ & 26 & $100 \%$ \\
\cline { 2 - 7 } & Altered & 0 & $0 \%$ & 0 & $0 \%$ \\
\hline \multirow{3}{*}{ ASAT } & Normal & 64 & $100 \%$ & 26 & $0 \%$ \\
\cline { 2 - 6 } & Altered & 0 & $0 \%$ & 0 & $0 \%$ \\
\hline \multirow{3}{*}{ ALAT } & Normal & 64 & $100 \%$ & 26 & $100 \%$ \\
\cline { 2 - 7 } & Altered & 0 & $0 \%$ & 0 & $0 \%$ \\
\hline \multirow{3}{*}{ Glucose } & Normal & 59 & $92.2 \%$ & 26 & $100 \%$ \\
\cline { 2 - 6 } & impared & 5 & $7.8 \%$ & 0 & $0 \%$ \\
\hline \multirow{2}{*}{ Blood pressure } & Normal & 41 & $35.9 \%$ & 23 & $88.5 \%$ \\
\cline { 2 - 6 } & impared & 23 & $64.1 \%$ & 3 & $11.5 \%$ \\
\hline
\end{tabular}


The results of the control examinations are collated in Table 12.

\section{Discussion}

BTK* capsules were found to still comply with the recommendations of the European Pharmacopoeia 14 months after their manufacture. This testifies to the seriousness which presided over their formulation. The absence of microorganisms confirms the antibacterial power of Garcinia kola nuts as reported by Morabandza et al in 2014 [14].

Systemic inflammation measured in daily clinical practice by CRP and SR exists in inflammatory diseases, particularly osteoarthritis. However, inflammation is very low in these mechanical diseases compared to inflammatory diseases. This justifies the choice of HS-CRP, which has the advantage of measuring infra-clinical inflammation and which, moreover, is little influenced by obesity like CRP [15].

The decrease in SR and HS-CRP show that BTK* capsules are as effective as DICLOFENAC on knee osteoarthritis and low back pain. Olayinka et al found that Garcinia kola $200 \mathrm{mg}$ is analgesic and anti-inflammatory but to a lesser degree than CELEBREX * and NAPROXENE * [10].

The reduction in pain assessed by VAS in patients on BTK * is consistent with the work of Olaleye et al [5] and Olayinka et al [10].

The increased libido recorded with Garcinia kola capsules had previously been observed by Ralebona et al [16].

The cases of drowsiness and constipation recorded in all groups can be attributed to the co-analgesics of the basic treatment which were prescribed for all patients.

The safety of Garcinia kola observed on the liver and kidney confirms the observations of Olayinka et al in 2008 [10].

The duration of exposure of the patients was short. With an exposure of at least 6 weeks and a much longer study duration, we could probably have appreciated the effect of Garcinia on cartilage by measuring cartilage markers such as urinary collagen type II C-telopeptide (UCTX -II), a marker of cartilage degradation, and serum hyaluronic acid, a marker of inflammation of the synovium [17]. A longer study period would also have made it possible to recruit more patients to consolidate these observations.

\section{Conclusion}

The aim of this study was to assess the anti-inflammatory effect of Garcinia kola capsules on knee osteoarthritis and low back pain compared to diclofenac. The statistically significant decrease in VAS, HS-CRP and ESR in the BTK * and diclofenac groups compared to the placebo group showed that at a daily dose of $800 \mathrm{mg}$, Garcinia kola capsules exhibit anti-inflammatory properties. Similar to those of diclofenac at a dose of $100 \mathrm{mg}$. Garcinia kola has good tolerance: it does not affect liver function, kidney function or blood sugar. Consumption of garcinia kola seeds in search of the aphrodisiac effect has found justification. The way is therefore open for the development of a good anti-inflammatory drug that is not aggressive for the stomach.

\section{Compliance with ethical standards}

\section{Disclosure of conflict of interest}

No conflict of interest.

\section{References}

[1] Buba CI, Okhale SE, Muazzam I. Garcinia kola: the phytochemistry, pharmacology and therapeutic application. Int J Pharmacognosy. 2016; 3(2): 67-81.

[2] Akpanta A, Oremosu A, Noronha C, Ekanem T, Okanlawon A. Effect of Garcinia kola seed extract on ovulation, estrous cycle and fetal development in cyclic female Sprague-dawley rat. Nigerien journal of physiological sciences. 2005; 20(1): 58-62. 
[3] Yété P, Ndayishimiye V, Agbangan P, Djènnontin $S$, Woto V, Sohounhloué D. Chemical Composition of the seeds and the Defatted Meal of Garcina kola Heckel from Benin. Chemistry journal. 2014; 4(5): 13-9.

[4] Falang KD, Uguru MO, Nkoli NL. Anti-piretic activity of garcinia kola seed extract. European J Med Plants. 2014; 4(5): 511-521.

[5] Olayele S, Farombi E, Owoyele B, Onasanwo S, Elegbe R. Analgesic and anti-inflammatory effect of kolaviron (a Garcinia kola seed extract). African journal of biomedical research. 2000; 3(3): 171-174.

[6] Ogunmoyole T, Olalekan O, Fatai O, Makun J, Kade L. Antioxidant and phytochemical profile of aqueous and ethanolic extract of Garcinia kola. Journal of pharmacognosy and phytotherapiy. 2012; 4(5): 66-74.

[7] Adaramoye O, Nwaneri V, Anyanwu K, Farombi E, Emerole G. possible qnti-atherogenic effect of kolaviron (a Garcinia kola seed extract) in hypercholesterolaemic rats. Clinical and experimental pharmacology and physiology. 2005; 32(1-2): 40-6.

[8] Udenze E, Braide V, Okwesilieze C, Akuodor G. Pharmacological Effect of Garcinia kola seed powder on blood sugar, lipid profile and Atherogenic index of Alloxan-induced diabetes in Rat. Pharmacologia. 3: 693-699.

[9] Essein GE, Nwafor PA. anticonceptive, estrogenic and antiestrogenic potential of methanol extract of Garcinia kola seed in rodents. Journal of Medicinal plants research. 2014; 8(42): 1237-44.

[10] Olayinka O Adegbehingle, Saburi A Adesanya, Thomas O , Idowu, Oluwakemi C Okimi, Oyesiku A Oyelami, Ezekiel O Iwalewa. Clinical effect of Garcinia kola in knee osteoarthritis. Journal of orthopedic surgery and research. 2008; 3: 34 .

[11] Neuro Sciences Musculoskeletal System Professor Ph. LAFFARGUE Roger Salengro Hospital Lille University Hospital. 2010.

[12] Doctor Yann Philippe CHARLES, Professor Jean-Paul STEIB, Department of Spine Surgery, Civil Hospital. La Lombalgie. 2013.

[13] Djoko E, Lanty W, Ngantchouko B, Tekam JM. Development of garcinia kola capsules. Internationnal journal of biological and pharmaceutical sciences Archive. 2021; 02(01): 184-193.

[14] Morabandza CJ, Ongoka AN, Okieli MG, Attibayeba A, Abena AA. Antimicrobial, anti-inflammatory and antioxidant effect of the mesocarp of Garcinia kola Heckel (Clusiaceae). PhytoTherapie. 2014; 12: 164-169.

[15] Sturmert, Brenner, Koening Wet al. severity and extent of osteoarthritis and low grade systems inflammation as assessed by high sensitivity C reactive protein. Annals of the rheumatic diseases. 2004; 63: 200-205.

[16] Ralebona N, Sewani-Rsike CR, Nkeh-Chungag BN. Effect of ethanolic extract of Garcinia kola on sexual behavior and sperm paramaters in male wistar rats. African journal of pharmacy and pharmacology. 15 April 2012; 6(4): 107-1082.

[17] Mclhwraith CW, Billingburst RC, Frisbie DD. Chirurgie-Arthrose. la presse Medicale. May 2004; 33(9): 13-15. 